\title{
Telomerase reverse transcriptase (TERT) expression and proliferation in canine brain tumours
}

\author{
S. Long*, D. J. Argylet, C. Nixon*, I. Nicholson*, C. Botteron‡, N. Olby§, S. Plattף, K. Smith**, \\ G. R. Ruttemant†, G. C. M. Grinwisł‡ and L. Nasir* \\ *Institute for Comparative Medicine, University of Glasgow Veterinary School, UK, †Royal (Dick) School of Veterinary \\ Clinical Studies, Easter Bush Veterinary Centre, Midlothian, UK, $¥$ Institute of Animal Neurology, University of Berne, \\ Berne, Switzerland, §College of Veterinary Medicine, North Carolina State University, NC, USA, $\uparrow$ Centre for Small Animal \\ Studies, Animal Health Trust, Newmarket, Suffolk, UK, **Centre for Preventive Medicine, Animal Health Trust, \\ Newmarket, Suffolk, UK, †tUtrecht University Clinic of Companion Animals, the Netherlands, ttDepartment of \\ Pathobiology, Faculty of Veterinary Medicine, Utrecht University, the Netherlands
}

S. Long, D. J. Argyle, C. Nixon, I. Nicholson, C. Botteron, N. Olby, S. Platt, K. Smith, G. R. Rutteman, G. C. M. Grinwis and L. Nasir (2006) Neuropathology and Applied Neurobiology 32, 662-673

Telomerase reverse transcriptase (TERT) expression and proliferation in canine brain tumours

Telomerase is a ribonucleoprotein enzyme complex that synthesizes telomere DNA. It is detected in $85-90 \%$ of malignant tumours in humans, but not in most somatic cells. Because telomerase plays a critical role in cell immortality, it represents an important target for anticancer therapies. We have previously shown that the dog is a potentially useful model for evaluating telomerase-based therapeutics. In this present study we analysed 93 canine brain tumours for telomerase reverse transcriptase (TERT) expression by immunohistochemistry. TERT immunoreactivity was detected in 16 of 50 grade 1 (32\%) and 29 of 43 grade 2 tumours $(67.4 \%)$, demonstrating a statistically significant association with histological grade $(P=0.00012)$. A subset of 51 tumours was also assessed for MIB-1 expression. The MIB-1 labelling index (LI) was found to correlate significantly with tumour grade, with a mean MIB-1 LI of $1.5 \%$ for grade 1 tumours, as compared with a mean MIB-1 LI of $21.7 \%$ for grade 2 tumours $(P<<0.001)$. The MIB-1 LI was also significantly associated with TERT expression in all brain tumours $(P<<0.001)$. These data further support the dog as a model for the preclinical development of telomerase-based therapeutics in brain tumours.

Keywords: brain tumours, dog, immunohistochemistry, Ki67, telomerase, TERT

\section{Introduction}

Telomerase is a cellular reverse transcriptase that adds nucleotides to the ends of telomeres, thereby preventing telomeric shortening and the onset of cellular senescence that occurs with the accumulation of cell divisions [1].

Correspondence: Sam Long, Section of Neurology and Neurosurgery, Department of Clinical Sciences, Philadelphia School of Veterinary Medicine, University of Pennsylvania, 3850 Spruce St, Philadelphia, PA 19104, USA. Tel: +1 1215573 9170; Fax: +1 1215573 6050; E-mail: longsn@vet.upenn.edu

662
Activity is essential for embryogenesis but is repressed upon tissue differentiation during development such that telomerase is absent from birth in most somatic tissues [2]. Some cell types, however, including male germ cells, activated lymphocytes and stem cell populations continue to express telomerase at reduced levels [3-5]. In contrast, $85-90 \%$ of human cancers possess telomerase activity (TA) [6,7]. The enzyme telomerase is composed of an RNA component (TR), a catalytic subunit [(telomerase reverse transcriptase (TERT)] and associated proteins [8,9]. The TERT component is considered the primary determinant

(C) 2006 Blackwell Publishing Ltd 
for activity for the following reasons: (1) TR is present in all tissues irrespective of TA [10]; (2) human TERT (hTERT) activity is repressed in normal somatic tissues, but expression is elevated in the majority of human tumours and in stem cells, correlating with TA [6]; (3) exogenous expression of hTERT in telomerase-negative normal human cells in vitro is associated with the presence of TA and with the extension of cellular lifespan $[11,12]$ and (4) the inhibition of hTERT expression represses TA and limits the lifespan of cancer cells [13].

Several studies have demonstrated that hTERT is a potentially useful diagnostic and prognostic marker for cancer $[14,15]$ as well as being an ideal target for therapy. To date the most successful telomerase-based therapeutic approaches that have been evaluated in preclinical trails have utilized the cancer specificity of telomerase gene expression to develop gene therapy strategies [16-18]. However, problems exist in taking these preclinical trials further, due to the lack of a suitable animal model. In mice, TA is present in all adult tissues and the telomerase subunits are not as tightly regulated as in human tissues $[19,20]$. Therefore the effects of tumour targeting therapies on normal tissues will probably be difficult to evaluate in mouse models. The presence of TA in canine tumour tissues has been investigated and these studies have analysed over 100 canine solid tumours demonstrating that more than $95 \%$ of canine cancers examined to date are associated with TA [21]. We have previously shown that TA in dogs is confined to tumour tissues and cells with a high proliferative potential (e.g. testis, lymphoid tissue) with little or no activity in normal somatic tissues [22]. Similarly, we have demonstrated that TA can be detected in immortal canine tumour cell lines and show that primary fibroblasts undergo telomeric attrition [22]. More recently, we have also shown that the dog TERT promoter is similar to the human promoter in terms of structure and tissuespecific activity [23]. Unlike other model systems, canine tumours arise spontaneously in a naturally outbred population. Many canine tumours share multiple histopathological features with human tumours and their biological behaviour in response to radiotherapy and chemotherapy is often similar [24]. These similarities not only suggest that TERT may be of diagnostic importance in canine malignancies but also provide support for the dog as a useful animal model for in vivo preclinical testing of novel therapies.

In particular, naturally occurring canine brain tumours occur with a frequency approximately five times greater than those in humans [25] with a reported incidence of 14.5 tumours per 100000 dogs compared with approximately 3-4 per 100000 people [26,27]. The most common types of primary brain tumours in dogs are meningiomas, comprising between $30 \%$ and $39 \%$ of all intracranial neoplasms [28,29], and glial tumours (astrocytomas and oligodendrogliomas). Pituitary tumours, choroid plexus papillomas and ependymomas are also commonly described. The majority of brain tumour types described in humans have been reported in dogs, and have shown to be both histopathologically and clinically similar to their human counterparts [26-30]. The aim of this study was to evaluate the presence of TERT protein expression in a range of formalin-fixed, paraffin-embedded canine brain tumour samples and to compare expression with proliferation as assessed by the MIB-1 labelling index (LI), to determine its usefulness as a diagnostic tool in canine brain tumours and to evaluate whether canine brain tumours provide a useful preclinical model for the evaluation of telomerase-based therapeutics.

\section{Materials and methods}

\section{Cell cultures}

CMT7 (kindly donated by Prof Hellmann, University of Uppsala) and D17 (ATTC: CRL-6248) canine cell lines were grown in DMEM (Invitrogen, Paisley, UK) supplemented with $10 \%$ foetal calf serum. In house cultured CSF-01 cells (canine primary skin fibroblasts) were grown in MEM- $\alpha$ (Invitrogen, Paisley, UK) supplemented with $10 \%$ foetal calf serum. The presence of TA in the CMT7 and D17 cells have previously been reported [22].

\section{Tissue samples}

Ninety-three formalin-fixed samples of brain tumours (Table 1) were retrieved from the pathology archives of the Institute for Comparative Medicine, University of Glasgow Veterinary School and collaborating Institutes, namely, Institute of Animal Neurology, University of Berne; College of Veterinary Medicine, North Carolina State University; Department of Pathobiology, Faculty of Veterinary Medicine Utrecht University; Centre for Small Animal Studies, Animal Health Trust, UK. All sections used in the study were reevaluated by a pathologist and the diagnosis 
Table 1. Correlation between telomerase reverse transcriptase (TERT) immunopositivity, tumour grade and tumour subtype. $P$-values show significance of correlation between percentage of TERT-positive tumours and grading (grade 1 or 2)

\begin{tabular}{|c|c|c|c|c|}
\hline Tumour type & Grade & No. & No. TERT +ve & P-value \\
\hline \multicolumn{5}{|l|}{ Astrocytomas } \\
\hline Astrocytoma & 1 & 5 & 0 & \\
\hline Astrocytoma anaplastic & 2 & 5 & 3 & \\
\hline \multirow[t]{2}{*}{ Astrocytoma glioblastoma } & 2 & 4 & 2 & \\
\hline & & 14 & $5(36 \%)$ & 0.10 \\
\hline \multicolumn{5}{|l|}{ Meningiomas } \\
\hline Meningioma & 1 & 21 & 8 & \\
\hline \multirow[t]{2}{*}{ Meningioma anaplastic } & 2 & 6 & 4 & \\
\hline & & 27 & $12(44 \%)$ & 0.008 \\
\hline \multicolumn{5}{|l|}{ Oligodendrogliomas } \\
\hline Oligodendroglioma & 1 & 17 & 7 & \\
\hline \multirow[t]{2}{*}{ Oligodendroglioma anaplastic } & 2 & 10 & 8 & \\
\hline & & 27 & $15(56 \%)$ & 0.004 \\
\hline \multicolumn{5}{|l|}{ Choroid plexus tumours } \\
\hline Choroid plexus papilloma & 1 & 6 & 0 & \\
\hline Choroid plexus papilloma: anaplastic & 2 & 1 & 1 & \\
\hline \multirow[t]{2}{*}{ Choroid plexus papilloma: carcinoma } & 2 & 1 & 0 & \\
\hline & & 8 & $1(13 \%)$ & 0.19 \\
\hline \multicolumn{5}{|l|}{ Other } \\
\hline Ependymoma & 1 & 1 & 1 & \\
\hline Gliosarcoma & 2 & 1 & 1 & \\
\hline Medulloblastoma & 2 & 1 & 1 & \\
\hline \multirow[t]{2}{*}{ Pituitary adenocarcinoma } & 2 & 1 & 1 & \\
\hline & & 4 & 4 & N/A* \\
\hline \multicolumn{5}{|l|}{ Metastases } \\
\hline Adenocarcinoma & 2 & 6 & 4 & \\
\hline \multirow[t]{2}{*}{ Lymphoma } & 2 & 7 & 4 & \\
\hline & & 13 & $8(61 \%)$ & $\mathrm{N} / \mathrm{A}^{*}$ \\
\hline \multicolumn{5}{|l|}{ All tumours } \\
\hline Grade 1 & & 50 & 16 & \\
\hline \multirow[t]{2}{*}{ Grade 2} & & 43 & 29 & \\
\hline & & 93 & 45 & 0.00012 \\
\hline
\end{tabular}

*Not applicable - insufficient group size (grade 1).

of intracranial neoplasia was confirmed. Each tumour sample was classified either as grade 1 or 2 using the World Health Organization classification system of tumours [30].

\section{Immunohistochemistry}

Paraffin-embedded samples were immunostained using a streptavidin-biotin complex. Paraffin sections were dewaxed in histo-clear (National Diagnostics, Atlanta, Georgia, USA), rehydrated in alcohol and incubated in 0.5\% $\mathrm{H}_{2} \mathrm{O}_{2}$ methanol solution for $20 \mathrm{~min}$. Cryostat sections were fixed in acetone before the quenching step. Paraffin sections were subjected to antigen retrieval with $0.01 \mathrm{M}$ sodium citrate $(\mathrm{pH} 6.0)$ in a pressure cooker $(75 \mathrm{~s}$ at 15 pounds per square inch). All sections were blocked in 1\% normal unlabelled serum (Scottish Antibody Production Unit, Edinburgh, UK) in $0.01 \mathrm{M}$ Tris-buffered saline for $30 \mathrm{~min}$ at room temperature and incubated for $2 \mathrm{~h}$ at room temperature with antibodies against hTERT (mouse monoclonal, BD Biosciences, diluted 1:200) and against Ki67 (MIB-1 mouse monoclonal, Dako, Ely, UK, 1:200 in $0.1 \% \mathrm{BSA})$. The sections were then incubated for $45 \mathrm{~min}$ with the appropriate biotinylated secondary antibody (DakoCytomation, Ely, UK) followed by horseradish peroxidase-conjugated streptavidin-biotin complex (DakoCytomation, Ely, UK) for 45 min. Immunoreactivity was visualized using diaminobenzidine (DAB) (Sigma, Gilling- 
ham, UK) and sections counterstained with haematoxylin. Negative controls were run in parallel without the primary antibody step.

\section{Evaluation of immunohistochemical staining}

The immunohistochemical staining was evaluated by light microscopy. For TERT staining, a staining percentage of greater than $10 \%$ was regarded as positive. For each section the distribution of staining within cells and throughout each section was noted. To assess MIB-1 LI, a minimum of five fields were selected from areas with the highest staining and a minimum of 1000 nuclei per case counted, with the number of positive cells being expressed as a percentage of all nuclei counted. For comparison of MIB-1 LI and TERT staining with histological grade, the Mann-Whitney U-test was used, with the level of significance set at $P<0.05$.

\section{Telomerase activity}

Telomerase activity was measured using the TeloTAGGG Telomerase PCR ELISA ${ }^{\text {PLUS }}$ assay (Roche Molecular Biochemicals, Lewes, UK). Briefly, cells were homogenized in $200 \mu \mathrm{l}$ of ice-cold lysis buffer and incubated for $30 \mathrm{~min}$ on ice. After centrifugation at $16000 \mathrm{~g}$ for $20 \mathrm{~min}$ at $4^{\circ} \mathrm{C}$, the supernatant was collected, frozen in liquid nitrogen, and stored at $-80^{\circ} \mathrm{C}$. Protein concentrations were measured using the Bradford assay (Sigma, Gillingham UK). Protein samples were incubated with reaction buffer containing a biotin-labelled P1-TS primer and P2 primer, telomerase substrate, and Taq polymerase for $30 \mathrm{~min}$ at $25^{\circ} \mathrm{C}$ in a final volume of $50 \mu \mathrm{l}$. Internal standard (IS) were included in each reaction to control for the presence of PCR inhibitors in protein extracts. After a further incubation at $94^{\circ} \mathrm{C}$ for $5 \mathrm{~min}$, the resulting mixture was subjected to PCR for 30 cycles of $30 \mathrm{~s}$ at $94^{\circ} \mathrm{C}, 30 \mathrm{~s}$ at $50^{\circ} \mathrm{C}$, and $90 \mathrm{~s}$ at $72^{\circ} \mathrm{C}$. The amplification products were denatured and hybridized with a digoxigenin-labelled, telomeric repeat-specific detection probe. The resulting product was immobilized through the biotin-labelled TS primer to a streptavidincoated microtitre plate and detected with an antidigoxigenin antibody conjugated with horseradish peroxidase. Absorbance values were measured using a microtitre reader at $450 \mathrm{~nm}$ with a reference wavelength of $690 \mathrm{~nm}$. Samples were regarded as telomerase positive if the absorbance was higher than 0.2 arbitrary units $\left(\mathrm{A}_{450 \mathrm{~nm}}{ }^{-}\right.$ $\left.\mathrm{A}_{690 \mathrm{~nm}}\right)$. The absorbance reading obtained with the posi- tive control supplied with the kit was always higher than $2.0 \mathrm{U}$.

\section{Results}

\section{Characterization of hTERT antibody cross reactivity in canine tissues}

We tested three commercially available anti-hTERT antibodies. Staining was performed with hTERT antibodies supplied by Oncogene (Anti-TERT, which recognizes an internal 21-amino-acid sequence), Novocastra (NCLhTERT, an antibody recognizing a 147-amino-acid sequence near the $\mathrm{N}$ terminal region of hTERT), and Alpha Diagnostics (EST-22A, an antibody directed against a 21amino-acid sequence found in the mid-region of hTERT) in formalin-fixed and paraffin-embedded canine tissues. Only one antibody (NCL-hTERT; Novacastra, Newcastle-UponTyne, UK) showed sufficient specificity in canine tissues and this antibody was used in all subsequent cross reactivity characterizations. To determine whether the antihTERT antibody (NCL-hTERT) could recognize canine TERT protein, TERT immunoreactivity was examined in D17 and CMT7 cells, and in canine testis tissue sections previously shown to be positive for TA [22]. Canine primary skin fibroblasts (CSF-01) cells negative for telomerase (data not shown) were used as negative controls. In both telomerase positive cell lines, TERT staining was restricted mainly to the nucleus (Figure 1A,B). Staining was particularly prominent in nucleoli, and in some cells, nucleolar staining was the only detectable pattern. In other cells, staining was distributed throughout the nucleus, either in a punctuate pattern or diffusely. Staining of the cytoplasm was also observed in some cells, although less intense than the nuclear staining. In normal canine testis, staining was confined to the germinal cells of the seminiferous tubules (Figure 1C). In contrast, no immunoreactivity was detected in the negative controls cells (Figure 1D).

\section{TERT immunohistochemistry in canine brain tumours}

To investigate expression of TERT in canine brain tumours, a total of 93 canine brain tumour sections were evaluated for TERT immunoreactivity using the NCLhTERT antibody. The staining pattern observed varied between tumours, with most tumours exhibiting granular nuclear staining with distinct nucleolar staining; in a few 

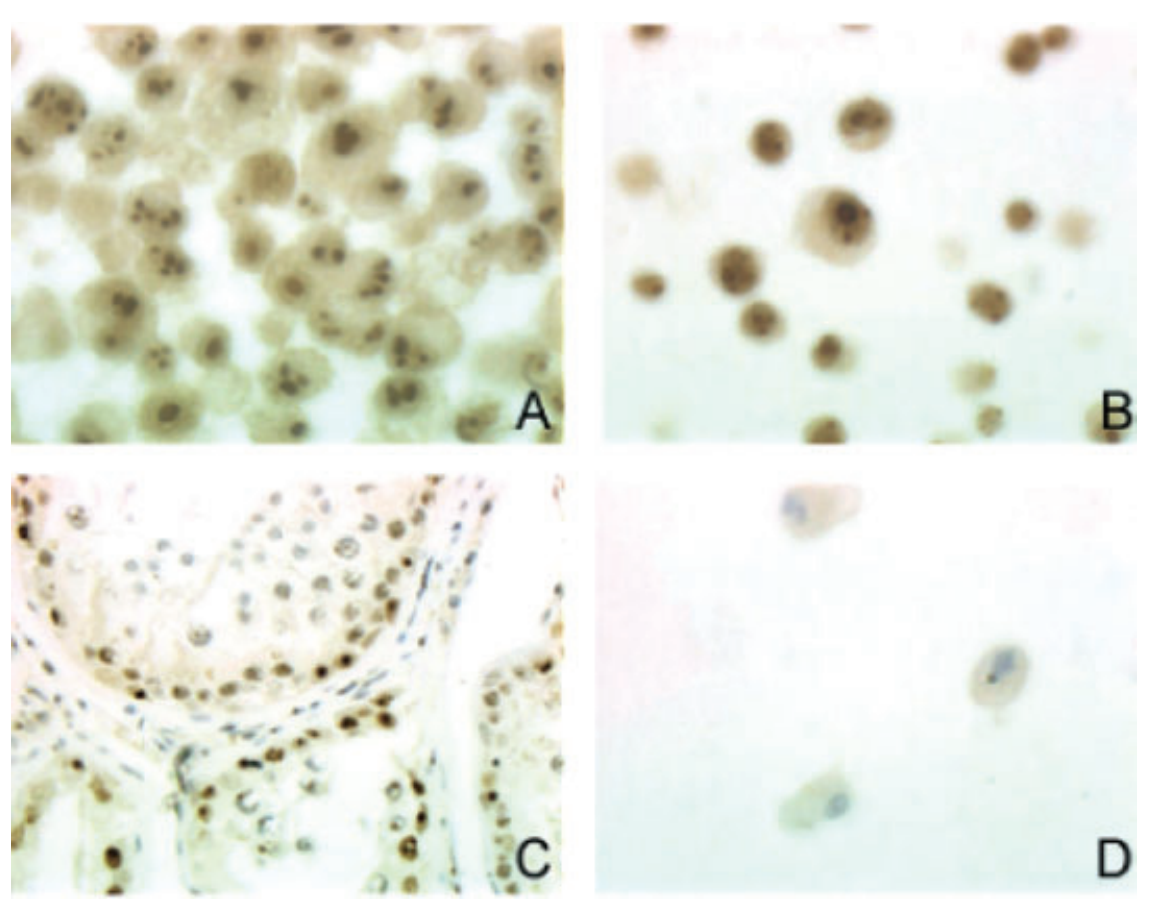

Figure 1. Telomerase reverse transcriptase (TERT) staining in canine cells and tissues. The presence of TERT protein is indicated by a brown signal. (A) TERT staining in canine telomerase positive D1 7 cells. Note strong nucleolar staining and fainter, more diffuse nucleoplasmic staining. (B) TERT staining in canine telomerase positive CMT7 cells. (C) TERT immunostaining localized to the germinal cells of the seminiferous tubules in canine testis CMT7 cells. (D) Negative TERT staining in canine primary fibroblasts. Magnification: A, B, D: $\times 400$; C: $\times 100$.

cases a more diffuse nuclear staining was seen. Representative examples of TERT staining observed are shown in Figure 2. Meningiomas (Figure 2B) and oligodendrogliomas (Figure 2C) tended to show a more diffuse staining pattern with the majority of cells within each tumour staining positive. In contrast, astrocytomas tended to exhibit a more patchy staining pattern, with some areas focally positive and the remainder of the tumour negative (Figure 2D). In some tumours staining was predominantly nucleolar (Figure 2E) while in others staining occurred more diffusely through the nucleus. In some glioblastomas, TERT staining was not restricted to tumour cells but was also found to be present in areas of vascular endothelial hyperplasia (Figure 2F). In these areas, endothelial cells stained positively, either with nucleolar staining or with a more diffuse nuclear localization. In addition, there appeared to be some background cytoplasmic staining in these cells. Faint background cytoplasmic staining was also found in choroid plexus papillomas which contain cells of endothelial origin.

As shown in Table 1, TERT immunoreactivity was detected in 45 of 93 (48\%) brain tumour tissues consisting of 16 of 50 grade $1(32 \%)$ and 29 of 43 grade 2 tumours $(67.4 \%)$, demonstrating a statistically significant association with histological grade overall $(P=0.00012)$. When metastases were excluded, the association between TERT immunoreactivity and grade remained statistically significant $(P=0.00014)$. TERT immunoreactivity was demonstrated in all tumour subtypes and a statistically significant association between TERT staining and histological grade was observed for meningiomas $(P=0.008)$ and oligodendrogliomas $(P=0.004)$ (Table 1$)$. TERT reactivity was observed least commonly in choroid plexus tumours where only one of eight tumours analysed was positive. The subgroup with the highest number of TERTpositive tumours were the metastatic tumours.

\section{MIB-1 immunohistochemistry and correlation with TERT expression}

Fifty-one of the canine brain tumours analysed for TERT immunopositivity were also evaluated for MIB-1. Immunoreactivity was exclusively confined to the nucleus with no evidence of cytoplasmic staining. Numerous strongly immunoreactive nuclei were found in all types of carcinoma cells (Figure 3). The MIB-1 LI was found to signifi- 

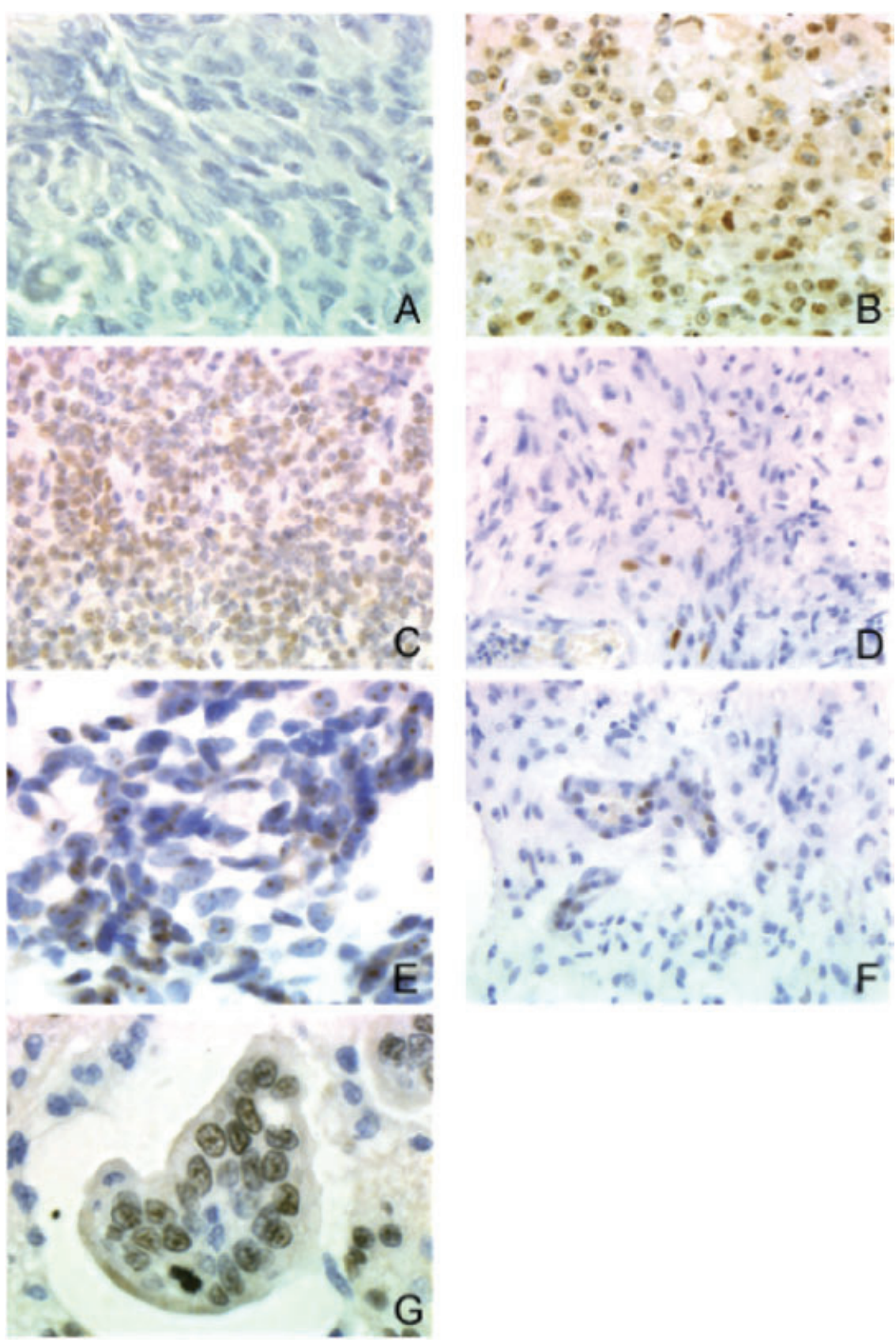

Figure 2. Telomerase reverse transcriptase (TERT) staining in canine brain tumours. (A) TERT-negative transitional meningioma. (B) TERTpositive anaplastic meningioma. (C) TERT-positive oligodendroglioma. Note diffuse distribution of positively stained cells. (D) TERT-positive anaplastic astrocytoma. Note majority of cells with predominant nucleolar staining. (E) TERT-positive glioblastoma. Note patchy distribution of positively stained cells with remainder of field TERT-negative. (F) Glioblastoma. Note positively staining vascular endothelial cells within a predominantly TERT-negative field. (G) Metastatic adenocarcinoma. Note single focus of metastatic cells within a TERT-negative section of normal brain. Magnification: A, B, D: ×200; C, E, F: ×100; G: ×400.

cantly associate with tumour grade, with a mean MIB-1 LI of $1.5 \%$ for grade 1 tumours, as compared with a mean MIB-1 LI of $21.7 \%$ for grade 2 tumours $(P<<0.001)$ (Table 2). A significant association was also observed between MIB-1 LI and TERT expression in all brain tumours $(P<<0.001)$ and in the meningioma and oligodendroglioma subtypes $(P=0.002$ and $P=0.007$ respectively) (Table 2). 

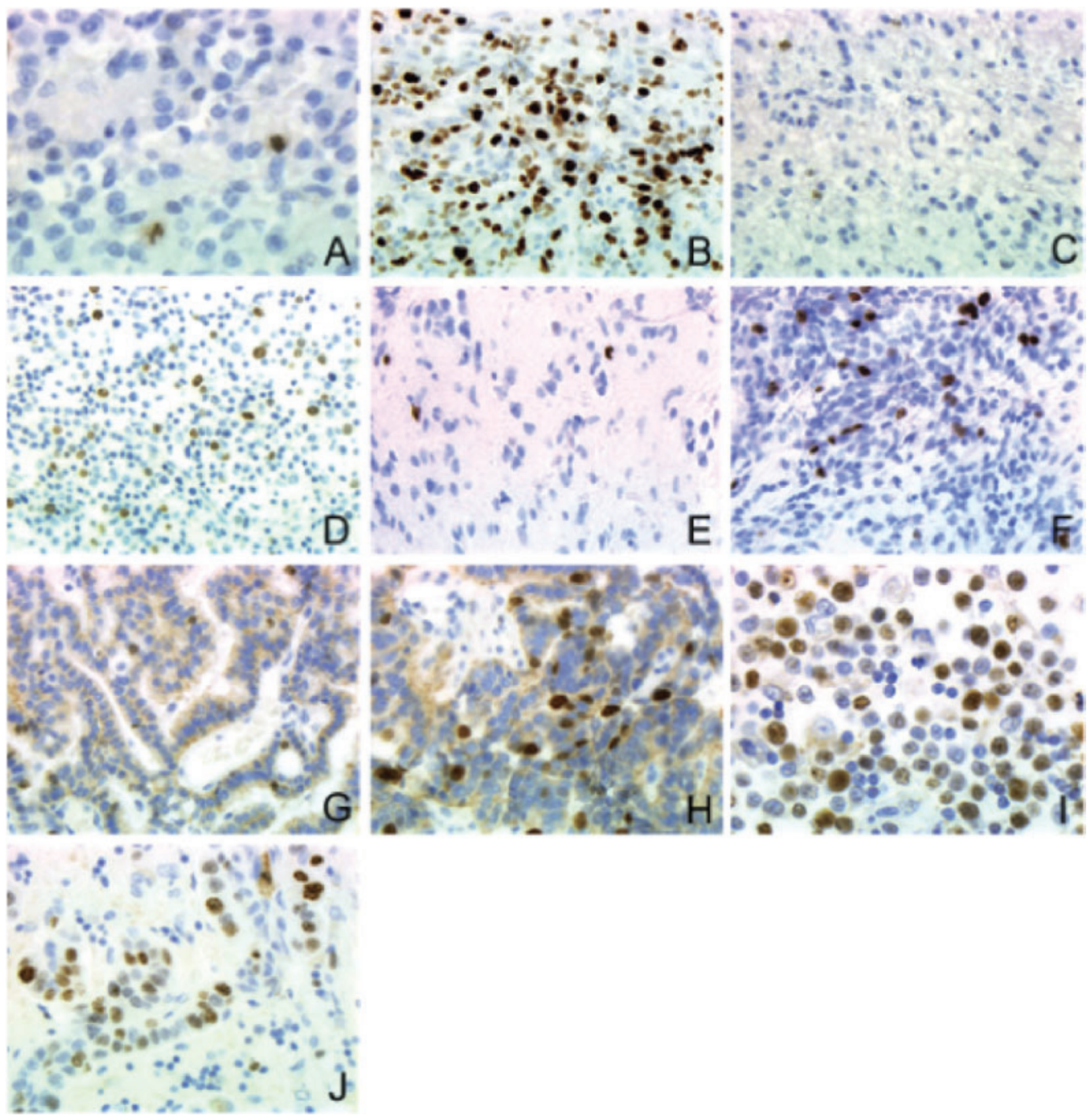

Figure 3. MIB-1 labelling index (LI) in canine brain tumours. (A) Meningioma ( $\mathrm{LI}=1.2)(\times 400)$. (B) Anaplastic meningioma (LI = 41.4) $(\times 200)$. (C) Oligodendroglioma $(\mathrm{LI}=2.8)(\times 200)$. (D) Anaplastic oligodendroglioma $(\mathrm{LI}=13.4)(\times 100)$. $(\mathrm{E})$ Astrocytoma $(\mathrm{LI}=3.2)(\times 200)$. (F) Anaplastic astrocytoma $(\mathrm{LI}=8.9)(\times 200)$. (G) Choroid plexus papilloma $(\mathrm{LI}=3.0)(\times 200)$. $(\mathrm{H})$ Choroid plexus carcinoma $(\mathrm{LI}=9.0)(\times 200)$. (I) Lymphoma (LI = 49.3) (×400). (J) Metastatic carcinoma $(\mathrm{LI}=10.4)(\times 200)$.

\section{Discussion}

We first characterized the antibody NCL-hTERT which recognizes a 147-amino-acid sequence near the $\mathrm{N}$ terminal region of hTERT, to determine cross reactivity with the canine TERT protein. Immunohistochemistry showed significant positive staining in canine cell lines previously reported to be positive for TA and the absence of staining in primary canine fibroblasts, previously shown to be TA negative [22]. Staining was also observed in normal 
Table 2. Correlation between mean MIB-1 staining, telomerase reverse transcriptase (TERT) immunopositivity, tumour grade and subtype. Pvalues show significance of correlation between MIB-1 labelling index and TERT positivity

\begin{tabular}{|c|c|c|c|c|c|c|}
\hline Tumour type & Grade & No. & Mean MIB-1 LI (\%) & MIB-1 range $(\%)$ & TERT +ve & P-value \\
\hline \multicolumn{7}{|l|}{ Astrocytomas } \\
\hline Astrocytoma & 1 & 1 & 3.2 & 3.2 & 0 & \\
\hline Astrocytoma anaplastic & 2 & 2 & 11.6 & $8.9-14.2$ & 1 & \\
\hline \multirow[t]{2}{*}{ Astrocytoma glioblastoma } & 2 & 2 & 22.9 & $19.6-26.1$ & 1 & \\
\hline & & 5 & & & 2 & 0.44 \\
\hline \multicolumn{7}{|l|}{ Meningiomas } \\
\hline Meningioma & 1 & 10 & 0.0 & $0-2.0$ & 0 & \\
\hline \multirow[t]{2}{*}{ Meningioma anaplastic } & 2 & 5 & 19.3 & $13.0-41.4$ & 4 & \\
\hline & & 15 & & & 4 & 0.0015 \\
\hline \multicolumn{7}{|l|}{ Oligodendrogliomas } \\
\hline Oligodendroglioma & 1 & 10 & 2.5 & $0-8.9$ & 2 & \\
\hline \multirow[t]{2}{*}{ Oligodendroglioma anaplastic } & 2 & 9 & 22.3 & $9.2-37.8$ & 8 & \\
\hline & & 19 & & & 10 & 0.007 \\
\hline \multicolumn{7}{|l|}{ Choroid plexus tumours } \\
\hline Choroid plexus papilloma & 1 & 5 & 0.8 & $0-0.3$ & 0 & \\
\hline \multirow[t]{2}{*}{ Choroid plexus papilloma: carcinoma } & 2 & 1 & 9.2 & N/A & 0 & \\
\hline & & 6 & & & 0 & 0.19 \\
\hline \multicolumn{7}{|l|}{ Other } \\
\hline Gliosarcoma & 2 & 1 & 26.1 & $\mathrm{~N} / \mathrm{A}^{*}$ & 1 & \\
\hline \multirow{2}{*}{ Pituitary adenocarcinoma } & 2 & 1 & 16.9 & $\mathrm{~N} / \mathrm{A}^{*}$ & 1 & \\
\hline & & 2 & & & 2 & $\mathrm{~N} / \mathrm{A} \dagger$ \\
\hline \multicolumn{7}{|l|}{ Metastases } \\
\hline Lymphoma & 2 & 3 & 47.1 & $19.4-72.5$ & 2 & \\
\hline \multirow[t]{2}{*}{ Adenocarcinoma } & 2 & 1 & 19.4 & $\mathrm{~N} / \mathrm{A}$ & 0 & \\
\hline & & 4 & & & 2 & $\mathrm{~N} / \mathrm{A} \dagger$ \\
\hline \multicolumn{7}{|l|}{ All tumours } \\
\hline Grade 1 & & 26 & 1.5 & $0-8.9$ & 2 & \\
\hline Grade 2 & & 25 & 21.7 & $8.9-72.5$ & 18 & \\
\hline Total & & 51 & & & 20 & $<<0.001$ \\
\hline
\end{tabular}

*Not applicable - insufficient sample size. †Not applicable - insufficient group size (grade 1).

canine testis tissue positive for TA, and the signal specifically localized as expected to the germinal cells of the seminiferous tubules. The immunoreactivity staining pattern seen in canine tumour cells is similar to that described in humans; most of the staining is confined to the nucleus, in a granular or diffuse pattern, with strong nucleolar localization [17,31-34]. The strong nucleolar staining is thought to represent detection of the telomerase holoenzyme, which is assembled within the nucleolus [33]. The granular or 'speckled' appearance throughout the nucleus may represent the active telomerase complex at chromosome ends [34]. Some authors have attempted to differentiate between those tumours in which nucleolar staining alone predominates from those in which nuclear and nucleolar staining occur. However, there would appear to be little clinical significance attached to the particular type seen [35]. The staining of endothelial cells may reflect a nonspecific interaction with the antibody, as several other antibodies stain cell cytoplasm in a nonspecific manner. Alternatively, the cytoplasmic staining may represent shuttling of the telomerase holoenzyme from the nucleus out to the cytoplasm and then back into the nucleus during the assembly process [35].

In addition the TERT staining patterns seen in human brain tumours are mirrored in canine brain tumours. In particular the more homogenous genetic make-up of oligodendroglial tumours appears to be reflected in the TERT staining pattern, with most TERT-positive oligodendrogliomas showing positive staining in the vast majority of cells diffusely throughout the tumour (Figure 2) [36]. The trend towards more focal, patchy TERT staining in astrocytomas also appears to parallel expression in human tumours [36]. This may reflect the evolution of these different tumour types. The fact that glioblastoma multi- 
forme may arise through one of several different pathways, either as a de novo tumour or as malignant transformation of more benign astrocytoma subtypes (secondary glioblastoma), demonstrates the genetic variation underlying this phenotype [37]. Some authors have suggested that telomerase activation occurs early in glioblastomas, and that with increasing tumour growth and the development of necrosis, TA subsequently disappears in some areas [38]. However, other authors have suggested that telomerase activation in these tumours occurs in areas of greater anaplasia, a finding which would support telomerase activation at a late stage in tumour development as anaplasia is more likely to occur later in tumour development [36]. Whether this pattern of telomerase loss with glioblastoma development occurs in dogs as well as in humans, however, remains to be investigated.

The finding that TERT is present in endothelial cells undergoing vascular endothelial hyperplasia has also been reported in humans [39,40]. The involvement of telomerase in tumour angiogenesis is likely to be the result of similar factors responsible for tumour development. For instance, the SP-1 transcription factor which is known to be important for the activation of TERT transcription, also acts on the promoter region of the Vascular Endothelial Growth Factor gene, a major player in the initiation of angiogenesis in glioblastomas as well as in other pathological situations [39].

In the present study, a MIB-1 LI of approximately $9 \%$ was found to be the cut-off between grade 1 and grade 2 tumours. In general, the majority of grade 1 tumours had a low MIB-1 LI, usually less than $4 \%$. One interesting finding was that two of the grade 2 meningiomas had a MIB1 LI of $>20 \%$; however, three had a substantially lower MIB-1 of between $9 \%$ and $14 \%$. In humans, the WHO classification includes three grades of meningioma: the benign, atypical and anaplastic variants. Of these, the atypical variant has been reported to have a MIB-1 LI of less than $20 \%$ while the anaplastic variant has a MIB-1 LI of greater than $20 \%$ [41]. In dogs, the current WHO classification describes only two variants: benign and anaplastic. Our results suggest that in dogs a third variant may be present based on a proliferative index of greater than $9 \%$ but less than $20 \%$, as described in humans. Further work examining a larger group of meningiomas and correlating survival with grading would be needed to confirm this. Interestingly, the tumour group with the highest MIB-1 LI was the metastatic tumour group, especially the lymphomas.
In the present study, TERT staining was associated with MIB-1 staining in the brain tumours assessed as a single group, as well as in the meningioma and oligodendroglioma subgroups. The association between MIB-1 staining and TA in human brain tumours is not entirely clear. While studies have found that TA is associated with proliferation, some studies have not [42]. Given that increased proliferation is the most useful prognostic indicator for many brain tumour types, and that TA is commonly associated with malignancy, it would be expected that these two characteristic features of tumours should overlap to some degree. However, it is not entirely clear whether the two factors are directly linked or whether they stem from a common determinant of tumour behaviour. It has been suggested that the vast majority of breast tumour cells undergoing proliferation also express telomerase, suggesting that at least in some tumour types the pathways initiating these two factors are shared by the same cells [14]. However, it is possible that telomerase activation may occur either before or after the signal to proliferate has been given. For instance, Maes et al. [35] found that TERT expression could be found in a subset of benign meningiomas, and that this predicted survival where proliferative index did not. This suggests that at least in these tumours TERT expression occurs before significant proliferation. Although in canine brain tumours overall we found a direct relationship between TERT expression and cellular proliferation, significant variation was found between the different tumour subtypes. For instance, one case of metastatic lymphoma exhibited the highest MIB-1 LI of $72.5 \%$, was found not to express TERT. In humans, the level of telomerase expression in metastatic brain tumours does not seem to correlate with either the tumour type or patient survival, although the majority of metastatic tumours do possess TA [43]. Our study appears to show a similar situation, with three out of four of the metastatic tumours examined being positive for TERT expression.

There is considerable evidence already from the human literature that TERT expression will indeed be a useful prognostic indicator. For example, in meningiomas, up to $20 \%$ of the most benign subtype will recur despite surgical resection. While proliferative markers do not predict those tumours which go on to recur, Maes et al. [35] found that TERT expression does, as recurrent tumours were found to have significantly more cells TERT-positive than nonrecurrent tumours. Simon et al. [44] reported similar findings, finding that all recurrent meningiomas in their study had 
acquired telomerase expression. Similarly, Harada et al. [45] found a similar situation in tracking a recurrent pituitary tumour, with successive resections of the same tumour showing an increasing level of TA. Studies examining TA within individual tumours as they progress are likely to provide useful information on tumour progression which is not necessarily available from surveying larger groups of tumours.

While our understanding of the biology of cancers has increased rapidly due to advances in molecular biology and genetics, such advances have not translated to the clinical setting at the same pace, largely because of the lack of preclinical in vivo model systems. Genetically engineered mice are excellent cancer models for translational research, but few have been involved in the preclinical development of novel therapeutics [46]. Telomerase is clearly a target for therapeutic intervention; however, in mice telomerase is present in all adult tissues, the telomerase subunits are not as tightly regulated as in human tissues $[19,20]$ and true tumour targeting will probably be difficult to demonstrate in mouse models. Dogs, however, represent useful animal models for cancer therapeutics; cancer in dogs is one of the major causes of death and occurs at a prevalence sufficient to be appropriate for preclinical trails. In the UK canine cancers occur at an estimated incidence of 1437 per 100000 dogs per year [47] and in the USA approximately 55 million dogs are estimated to be at risk of developing cancer [24]. We have previously shown that TA (in terms of its tissue specific distribution) is similar in dogs as in humans and telomere lengths are also comparable in size [22]. Further, we have recently demonstrated that the canine TERT promoter is also similar to the human promoter in structure and activity [23]. The present study demonstrates that TERT expression shows strong similarities in canine brain tumours to human tumours and this datum is not only important in terms of diagnostics in canine brain malignancies but also further supports the dog as a preclinical model system for telomerase-based therapeutics.

\section{Acknowledgements}

This work was in part funded by the Waltham Foundation. The authors would also like to acknowledge the support and advice given by Dr Susan Robinson, Institute of Neurosciences, Southern General Hospital, Glasgow, UK.

\section{References}

1 Shay JW, Wright WE. Senescence and immortalization: role of telomeres and telomerase. Carcinogenesis 2005; 26: 867-74

2 Wright WE, Piatyszek MA, Rainey WE, Byrd W, Shay JW. Telomerase activity in human germline and embryonic tissues and cells. Dev Genet 1996; 18: 173-9

3 Broccoli D, Young JW, de Lange T. Telomerase activity in normal and malignant hematopoietic cells. Proc Natl Acad Sci USA 1995; 92: 9082-6

4 Counter CM, Gupta J, Harley CB, Leber B, Bacchetti S. Telomerase activity in normal leukocytes and in hematologic malignancies. Blood 1995; 85: 2315-20

5 Hiyama K, Hirai Y, Kyoizumi S, Akiyama M, Hiyama E, Piatyszek MA, Shay JW, Ishioka S, Yamakido M. Activation of telomerase in human lymphocytes and hematopoietic progenitor cells. J Immunol 1995; 155: 3711-5

6 Kim NW, Piatyszek MA, Prowse KR, Harley CB, West MD, Ho PL, Coviello GM, Wright WE, Weinrich SL, Shay JW Specific association of human telomerase activity with immortal cells and cancer. Science 1994; 266: 2011-5

7 Shay JW, Bacchetti S. A survey of telomerase activity in human cancer. Eur J Cancer 1997; 33: 787-91

8 Meyerson M, Counter CM, Eaton EN, Ellisen LW, Steiner P, Caddle SD, Ziaugra L, Beijersbergen RL, Davidoff MJ, Liu Q, Bacchetti S, Haber DA, Weinberg RA. hEST2, the putative human telomerase catalytic subunit gene, is upregulated in tumor cells and during immortalization. Cell 1997; 90: 785-95

9 Nakamura TM, Morin GB, Chapman KB, Weinrich SL, Andrews WH, Lingner J, Harley CB, Cech TR. Telomerase catalytic subunit homologs from fission yeast and human. Science 1997; 277: 955-9

10 Avilion AA, Piatyszek MA, Gupta J, Shay JW, Bacchetti S, Greider CW. Human telomerase RNA and telomerase activity in immortal cell lines and tumor tissues. Cancer Res 1996; 56: 645-50

11 Bodnar AG, Ouellette M, Frolkis M, Holt SE, Chiu CP, Morin GB, Harley CB, Shay JW, Lichtsteiner S, Wright WE. Extension of life-span by introduction of telomerase into normal human cells. Science 1998; 279: 349-52

12 Counter CM, Meyerson M, Eaton EN, Ellisen LW, Caddle SD, Haber DA, Weinberg RA. Telomerase activity is restored in human cells by ectopic expression of hTERT (hEST2), the catalytic subunit of telomerase. Oncogene 1998; 16: 1217-22

13 Hahn WC, Stewart SA, Brooks MW, York SG, Eaton E, Kurachi A, Beijersbergen RL, Knoll JH, Meyerson M, Weinberg RA. Inhibition of telomerase limits the growth of human cancer cells. Nat Med 1999; 5: 1164-70

14 Ikeda S, Shibata T, Eishi Y, Takizawa T, Koike M. Correlation between the expression of telomerase reverse transcriptase and proliferative activity in breast cancer cells using an immunocytochemical restaining method. Pathol Int 2003; 53: 762-8 
15 Cabuy E, de Ridder L. Telomerase activity and expression of telomerase reverse transcriptase correlated with cell proliferation in meningiomas and malignant brain tumors in vivo. Virchows Arch 2001; 439: 176-84

16 Plumb JA, Bilsland A, Kakani R, Zhao J, Glasspool RM, Knox RJ, Evans TR, Keith WN. Telomerase-specific suicide gene therapy vectors expressing bacterial nitroreductase sensitize human cancer cells to the pro-drug CB1954. Oncogene 2001; 20: 7797-803

17 Komata T, Kondo Y, Kanzawa T, Hirohata S, Koga S, Sumiyoshi H, Srinivasula SM, Barna BP, Germano IM, Takakura M, Inoue M, Alnemri ES, Shay JW, Kyo S, Kondo S. Treatment of malignant glioma cells with the transfer of constitutively active caspase- 6 using the human telomerase catalytic subunit (human telomerase reverse transcriptase) gene promoter. Cancer Res 2001; 61: 5796-802

18 Bilsland AE, Anderson CJ, Fletcher-Monaghan AJ, McGregor F, Evans TR, Ganly I, Knox RJ, Plumb JA, Keith WN. Selective ablation of human cancer cells by telomerase-specific adenoviral suicide gene therapy vectors expressing bacterial nitroreductase. Oncogene 2003; 22: 370-80

19 Martin-Rivera L, Herrera E, Albar JP, Blasco MA. Expression of mouse telomerase catalytic subunit in embryos and adult tissues. Proc Natl Acad Sci USA 1998; 95: 10471-6

20 Greenberg RA, Allsopp RC, Chin L, Morin GB, DePinho RA. Expression of mouse telomerase reverse transcriptase during development, differentiation and proliferation. Oncogene 1998; 16: 1723-30

21 Argyle DJ, Nasir L. Telomerase: a potential diagnostic and therapeutic tool in canine oncology. Vet Pathol 2003; 40: $1-7$

22 Nasir L, Devlin P, Mckevitt T, Rutteman G, Argyle DJ. Telomere lengths and telomerase activity in dog tissues: a potential model system to study human telomere and telomerase biology. Neoplasia 2001; 3: 351-9

23 Long S, Argyle DJ, Campbell S, Gault E, Nasir L. The canine telomerase catalytic subunit (dogTERT): characterisation of the gene promoter and identification of proximal core sequences necessary for specific transcriptional activity in canine telomerase positive cell lines. Gene 2005; 358: 111-20

24 Vail DM, MacEwan EG. Spontaneously occurring tumors of companion animals as models for cancer. Cancer Invest 2000; 18: 781-92

25 Keller ET, Madewell BR. Locations and types of neoplasms in immature dogs: 69 cases (1964-89). J Am Vet Med Assoc 1992; 200: 1530-2

26 Morrison WB. Cancer affecting the nervous system. In Cancer in Dogs and Cats. Ed. WB Morrison. Baltimore, MD: Williams and Wilkins 1998, 655-65

27 Turrel JM, Fike JR, LeCouteur RA, Higgins RJ. Computed tomographic characteristics of primary brain tumors in 50 dogs. J Am Vet Med Assoc 1986; 188: 851-6
28 Braund KG, Ribas JL. Central nervous system meningiomas. Compendium Continuing Education 1986; 8: 241-8

29 Heidner GL, Kornegay JN, Page RL, Dodge RK, Thrall D. Analysis of survival in a retrospective study of 86 dogs with brain tumors. J Vet Intern Med 1991; 5: 219-26

30 Koestner A, Bilzer T, Fatzer R, Schulman FY, Summers BA, Van Winkle TJ. Histological Classification of Tumours of the Nervous System of Domestic Animals. Washington, DC: Armed Forces Institute of Pathology, 1999

31 Poremba C, Scheel C, Hero B, Christiansen H, Schaefer K, Nakayama J, Berthold F, Juergens H, Boecker W, Dockhorn-Dworniczak B. Telomerase activity and telomerase subunit gene expression patterns in neuroblastoma: a molecular and immunohistochemical study establishing prognostic tools for fresh-frozen and paraffin-embedded tissues. J Clin Oncol 2000; 18: 2582-92

32 Yan P, Benhattar J, Seelentag W, Stehle J-C, Bosman FT. Immunohistochemical localization of hTERT protein in human tissues. Histochem Cell Biol 2004; 121: 391-7

33 Smith DL, Soria JC, Morat L, Yang Q, Sabatier L, Liu DD, Nemr RA, Rashid A, Vauthey JN. Human telomerase reverse transcriptase (hTERT) and Ki-67 are better predictors of survival than established clinical indicators in patients undergoing curative hepatic resection for colorectal metastases. Ann Surg Oncol 2004; 11: 45-51

34 Kyo S, Masutomi K, Maida Y, Kanaya T, Yatabe N, Nakamura H, Tanaka M, Takarada M, Sugawara I, Murakami S, Taira T, Inoue H. Significance of immunological detection of human telomerase reverse transcriptase: re-evaluation of expression and localization of telmomerase reverse transcriptase. Am J Pathol 2003; 163: 859-67

35 Maes L, Lippens E, Kalala JP, de Ridder L. The hTERTprotein and Ki-67 labelling index in recurrent and nonrecurrent meningiomas. Cell Prolif 2005; 38: 3-12

36 Kleinschmidt-DeMasters BK, Hashizumi TL, Sze CI, Lillehei KO, Shroyer AL, Shroyer KR. Telomerase expression shows differences across multiple regions of oligodendroglioma versus high grade astrocytomas but shows correlation with Mib-1 labelling. J Clin Pathol 1998; 51: 28493

37 Harada K, Kurisu K, Tahara H, Tahara E, Ide T. Telomerase activity in primary and secondary glioblastomas multiforme as a novel molecular tumor marker. J Neurosurg 2000; 93: 618-25

38 Falchetti ML, Pallini R, D’Ambrosio E, Pierconti F, Martini M, Cimino-Reale G, Verna R, Maira G, Larocca LM. In situ detection of telomerase catalytic subunit mRNA in glioblastoma multiforme. Int J Cancer 2000; 88: 895-901

39 Falchetti ML, Pierconti F, Casalbore P, Maggiano N, Levi A, Larocca LM, Pallini R. Glioblastoma induces vascular endothelial cells to express telomerase in vitro. Cancer Res 2003; 63: 3750-4

40 Pallini R, Pierconti F, Falchetti ML, D'Arcangelo D, Fernandez E, Maira G, D'Ambrosio E, Larocca LM. Evidence for telomerase involvement in the angiogenesis of astrocytic tumors: expression of human telomerase 
reverse transcriptase messenger RNA by vascular endothelial cells. J Neurosurg 2001; 94: 961-71

41 Ho DM, Hsu CY, Ting LT, Chiang H. Histopathology and MIB-1 labeling index predicted recurrence of meningiomas: a proposal of diagnostic criteria for patients with atypical meningioma. Cancer 2002; 94: 1538-47

42 Nakatani K, Yoshimi N, Mori H, Yoshimura S, Sakai H, Shinoda J, Sakai N. The significant role of telomerase activity in human brain tumors. Cancer 1997; 80: 471-6

43 Kleinschmidt-DeMasters BK, Shroyer AL, Hashizumi TL, Evans LC, Markham N, Kindt G, Shroyer KR, Part I. Telomerase levels in human metastatic brain tumors show four-fold logarithmic variability but no correlation with tumor type or interval to patient demise. J Neurol Sci 1998; 161: 116-23

44 Simon M, Park TW, Leuenroth S, Hans VH, Loning T, Schramm J. Telomerase activity and expression of the telomerase catalytic subunit, hTERT, in meningioma progression. J Neurosurg 2000; 92: 832-40

45 Harada K, Kazunori A, Kurisu K, Tahara E. Telomerase activity and the expression of telomerase components in pituitary adenoma with malignant transformation. Surg Neurol 2000; 53: 267-74

46 Hansen K, Khanna C. Spontaneous and genetically engineered animal models: use in preclinical cancer drug development. Eur J Cancer 2004; 40: 858-80

47 Dobson JM, Samuel S, Milstein H, Rogers K, Wood JL. Canine neoplasia in the UK: estimates of incidence rates from a population of insured dogs. J Small Anim Pract 2002; 43: 240-6

Received 2 March 2006

Accepted after revision 12 June 2006 